\title{
Generalized Anxiety Disorders among Cases with Diabetes Mellitus
}

\author{
SAIF-UL-ISLAM ${ }^{1}$, SYED ARSALAN HAIDER ${ }^{2}$, ATHAR IQBAL ${ }^{3}$, MUHAMMAD NAEEM AKHTAR ${ }^{4}$, MUNAZZA JAVED ${ }^{5}$, \\ NADIR HUSSAIN ${ }^{6}$ \\ ${ }^{1}$ Medical Officer, Shaikh Zayed Hospital, Rahim Yar Khan \\ ${ }^{2}$ Assistant Professor, Punjab Institute of Neurosciences, Lahore \\ ${ }^{3}$ Senior Registrar, Shaikh Zayed Post Graduate Medical Institute, Lahore \\ ${ }^{4}$ Registrar Pulmonolgy, Lahore General Hospital, Lahore \\ ${ }^{5}$ Associate Professor, Azra Naheed Medical College, Lahore. \\ ${ }^{6}$ Resident Neurology, Punjab Institute of Neurosciences, Lahore \\ Correspondence to Dr. Athar lqbal, Email: athariqbalraja@gmail.com, Cell: 0333-7826952
}

\begin{abstract}
Background: Diabetes mellitus is one of the highly prevalent chronic diseases that can impact the life greatly, not only by its own disease process, but also due to wide range of other social and psychological effects on one's life. Generalized anxiety disorder is one of these complications, but is highly under rated.

Aim: To determine the frequency of generalized anxiety disorder (GAD) among cases with Diabetes Mellitus presenting to out-patient Diabetes clinic of Lahore General Hospital, Lahore.

Place and duration of study: This study was carried out in the Department of Medicine, Lahore General Hospital, Lahore from 10-06-18 to 10-06-19.

Methodology: This was a cross sectional study. The cases with both gender and age range of 30 to 60 years with known history of DM for at least one year were included. Anxiety was labelled on the basis of GAD scale and score of 5 or more was labelled as yes.

Results: In this study there were total 192 cases of DM and out of them $98(51.04 \%)$ were males. The mean age of the subjects was $51.20 \pm 8.16$ years and mean $\mathrm{HbA1c}$ level was $8.78 \pm 2.34$. There were $127(66.15 \%)$ cases with type II DM, and only 28(14.58\%) had controlled DM. Generalized anxiety disorder was seen in $72(37.50 \%)$ of cases. GAD was significantly high in females affecting 44 out of 94 cases with $p=0.03$. The cases with duration of $\mathrm{DM}$ of 5 or more years had GAD significantly high (64 out of 120) cases with $p=0.01$. The cases who were unemployed had significantly higher number of cases suffering from GAD; affecting 58 out of 106 with $p=0.01$.

Conclusion: GAD is common and seen in almost more than every $3^{\text {rd }}$ case suffering from DM and those with DM for 5 years or more, un-employed or those who were widow or divorced had it significantly high.

Keywords: DM, GAD, HbA1c
\end{abstract}

\section{INTRODUCTION}

Diabetes mellitus is a complex metabolic condition in which either defect in insulin release or insulin sensitivity or both leads to persistence of hyperglycemic state. The chronic hyperglycemia of diabetes is associated with long-term damage, dysfunction and failure of various organs, especially the eyes, kidneys, nerves, heart and blood vessels. As per a report by the World Health Organization, the prevalence of diabetes in all age categories worldwide was reported to be $2.8 \%$ in 2000 and was predicted $4.4 \%$ in $2030 .{ }^{1}$ Generalized anxiety disorder (GAD) is common in both community and clinical settings. Epidemiologic studies of nationally representative samples in the United States have found a lifetime prevalence of GAD of $5.1 \%$ to $11.9 \%$. A review of epidemiological studies in Europe found a 12month prevalence of 1.7 to $3.4 \%$ and a lifetime prevalence of 4.3 to $5.9 \%$.

GAD is a very frequent mental health issue with a tremendous disease burden on the health system. In a study of adult primary care patients in four Nordic countries, the rates of GAD were 4.1 to $6.0 \%$ among men, and 3.7 to $7.1 \%$ among women ${ }^{2-8}$. GAD is twice more prevalent in women than in men. It is probably the most common anxiety disorder among the elderly population ${ }^{8,9}$. Evidence suggest the bidirectional relationship between

Received on 23-12-2020
Accepted on 17-04-2021

diabetes and depression with earlier life depression contributing to increased risk of diabetes and vice versa. The emotional and social impact of diabetes and the demands of therapy may cause significant psychosocial dysfunction in patients and their families. It has been indiucated in a five years prospective cohort study that diabetic patients with severe depression have increased risk of significant macrovascular and microvascular complications $^{10}$.

Furthermore, several studies show that comorbid depression is linked with poor endearment to lifestyle modifications ${ }^{11}$, high cost ${ }^{12}$ and increased mortality among diabetic patients. There is two times increased risk of depression among diabetic patients as compared to general population ${ }^{13}$.

\section{MATERIALS AND METHODS}

After approval from local ethical review committee, total 192 cases with DM as per operational definition presenting to Diabetes Clinic of Lahore General Hospital, Lahore fulfilling the inclusion criteria were included in this study. An informed consent was taken to collect data and to include in the study. Socio demographic data like age (in years), gender (male/female) was taken and other data like duration of DM (years), type of DM (type I or II assessed by their medical record), control of DM (controlled/ 
uncontrolled), socioeconomic status (good if earning more than 30 thousand and poor if salary less than this assessed by history), employment status (working or not assessed by history employment card), marital status (married/ unmarried/widow/divorced assessed by history) and educational status (educated if grade 10 or more assessed by history) was also taken. Then these cases filled the GAD 7 scale by themselves if educated and by the medical officer if uneducated in the Diabetes clinic with at least 1 year experience after internship. The proforma was collected and the medical officer counted the score and results were recorded on the same proforma. GAD was labelled yes when there was score of 5 or more on GAD 7 scale.

Quantitative variables like age, duration of DM, $\mathrm{HbA1c}$ score and score on GAD 7 scale was presented as mean $\pm S D$ (standard deviation). Qualitative variables like gender, type of DM (I or II), control of DM (controlled/uncontrolled) educational status (educated/not educated), employment status (employed/ unemployed), marital status (married/ unmarried/ widow/divorced), socioeconomic status (good/poor) and outcome variable i.e. anxiety detected (yes/no) were presented as frequencies and percentages. Stratification was done on the basis of age, gender, type of DM, duration of DM, control of DM, educational status, employment status, marital status and socioeconomic status to see its effect on outcome variable i.e. anxiety. Post stratification chi-square test was applied and $p \leq 0.05$ was taken as significant.

\section{RESULTS}

In this study there were total 192 cases of DM and out of them 98 (51.04\%) were males (Table 1$)$. The mean age of the subjects was $51.20 \pm 8.16$ years and mean duration of DM was $5.87 \pm 3.67$ years as shown in table $1 \& 2$. Mean $\mathrm{HbA1c}$ level was $8.78 \pm 2.34$ (Table 3 ). There were $127(66.15 \%)$ cases with type II DM, and only $28(14.58 \%)$ had controlled DM. The educational, marital, employment and socioeconomic status of study subjects. Mena score of GAD scoring system was $7.78 \pm 3.21$ as in table 04 . Generalized anxiety disorder was seen in $72(37.50 \%)$ of cases.

Figure 1: Gender distribution $(n=192)$

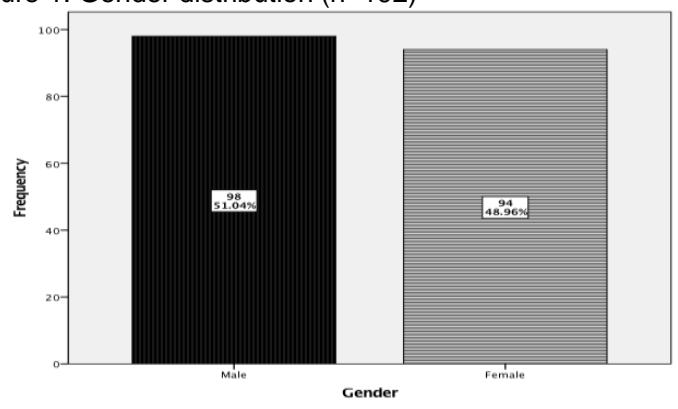

GAD was significantly high in females affecting 44 out of 94 cases with $p=0.03$ while no difference among different age groups with $p=0.78$ (Table 5 ). There was no significant difference in terms of type of DM $(p=0.41)$ while the cases with duration of DM of 5 or more years had GAD significantly high (64 out of 120 ) cases with $p=0.01$ (Table
6). There was no significant difference in terms of control of DM and socioeconomic status (Table 7). Education status was not associated with any difference $(p=0.23)$. Regarding development of GAD while the cases who were unemployed had significantly higher number of cases suffering from this; affecting 58 out of 106 with $p=0.01$. regarding marital status, the cases, those were widow and divorced had highest number of cases with GAD i.e. 10 out of 14 and 9 out of 12 respectively with $p=0.001$ as displayed (Table 9).

Table 1: Age in study subjects $(n=192)$

\begin{tabular}{|l|c|}
\hline & Age (years) \\
\hline Mean & 51.20 \\
\hline Std. Deviation & 8.16 \\
\hline Minimum & 30 \\
\hline Maximum & 60 \\
\hline
\end{tabular}

Table 2: Duration of DM in study subjects

\begin{tabular}{|l|c|}
\hline & Duration of DM (years) \\
\hline Mean & 5.87 \\
\hline Std. Deviation & 3.67 \\
\hline Minimum & 2 \\
\hline Maximum & 20 \\
\hline
\end{tabular}

Table 3: HBA1C in study subjects $(n=192)$

\begin{tabular}{|l|c|}
\hline & HbA1c \\
\hline Mean & 8.78 \\
\hline Std. Deviation & 2.34 \\
\hline Minimum & 5 \\
\hline Maximum & 12 \\
\hline
\end{tabular}

Table 4: Score on GAD in study subjects

\begin{tabular}{|l|c|}
\hline & GAD score \\
\hline Mean & 7.78 \\
\hline Std. Deviation & 3.21 \\
\hline Minimum & 0 \\
\hline Maximum & 16 \\
\hline
\end{tabular}

Table 5: GAD in study subjects with respect to gender and age

\begin{tabular}{|l|c|c|l|l|}
\hline \multirow{2}{*}{ Gender } & \multicolumn{2}{|c|}{ GAD } & \multirow{2}{*}{ Total } & P value \\
\cline { 2 - 3 } & Yes & No & & \\
\hline Male & 28 & 70 & 98 & \multirow{2}{*}{0.03} \\
\hline Female & 44 & 50 & 94 & \\
\hline Age group & 23 & 44 & 67 & 0.78 \\
\hline $30-45$ & 49 & 76 & 125 & \\
\hline $46-60$ &
\end{tabular}

Table 6: GAD in study subjects with respect to type and duration of DM

\begin{tabular}{|l|l|l|l|l|}
\hline \multirow{2}{*}{ Type of DM } & \multicolumn{2}{|c|}{ GAD } & \multirow{2}{*}{ Total } & \multirow{2}{*}{ P value } \\
\cline { 2 - 4 } & Yes & No & & \\
\hline I & 24 & 41 & 65 & \multirow{2}{*}{0.41} \\
\hline II & 48 & 79 & 127 & \\
\hline Duration of DM & 8 & 64 & 72 & 0.01 \\
\hline$<5$ year & 8 & 56 & 120 & \\
\hline 5 or more & 64 &
\end{tabular}

Table 7: GAD in study subjects with respect to control of DM and socioeconomic status

\begin{tabular}{|l|c|l|l|l|}
\hline \multirow{2}{*}{ Control of DM } & \multicolumn{2}{|c|}{ GAD } & \multirow{2}{*}{ Total } & P value \\
\cline { 2 - 3 } & Yes & No & & \\
\hline Controlled & 9 & 19 & 28 & \multirow{2}{*}{0.56} \\
\hline Uncontrolled & 63 & 101 & 164 & \\
\hline Socioeconomic status & 18 & 38 & 56 & 0.51 \\
\hline Good & \multicolumn{5}{|l}{} \\
\hline
\end{tabular}




\begin{tabular}{|c|c|c|c|c|}
\hline Poor & \begin{tabular}{l|l}
54 &
\end{tabular} & 82 & 36 & \\
\hline \multicolumn{5}{|c|}{$\begin{array}{l}\text { Table 8: GAD in study subjects with respect to educational and } \\
\text { employment status }\end{array}$} \\
\hline \multirow{2}{*}{$\begin{array}{l}\text { Educational } \\
\text { status }\end{array}$} & \multicolumn{2}{|c|}{ GAD } & \multirow[t]{2}{*}{ Total } & \multirow{2}{*}{$P$ value } \\
\hline & Yes & No & & \\
\hline Educated & 17 & 56 & 73 & \multirow{2}{*}{0.03} \\
\hline Non educated & 55 & 64 & 119 & \\
\hline \multicolumn{5}{|c|}{ Employment status } \\
\hline Employed & 14 & 72 & 86 & \multirow[t]{2}{*}{0.01} \\
\hline Unemployed & 58 & 48 & 106 & \\
\hline
\end{tabular}

Table 9: GAD in study subjects with respect to marital status

\begin{tabular}{|l|c|c|c|}
\hline Socioeconomic & \multicolumn{2}{|c|}{ GAD } & Total \\
\cline { 2 - 3 } & Yes & No & \\
\hline Married & 50 & 107 & 157 \\
\hline Unmarried & 3 & 6 & 9 \\
\hline Widow & 10 & 4 & 14 \\
\hline Divorced & 9 & 3 & 12 \\
\hline
\end{tabular}

$P$ value 0.001

\section{DISCUSSION}

The number of cases with Diabetes Mellitus is increasing day by day; courtesy the change in life style and decrease in physical activities associated with more of dietary habits leading to higher BMI. Currently worldwide 285 million people are suffering from diabetes mellitus and it is estimated that the numbers will rise upto 438 million by the year 2030. Ironically $70 \%$ of these people are from developing countries ${ }^{1-2}$. DM is a chronic disease and can result in a wide array of complications that can virtually involve any part of the body. In addition to this it is fairly established that development of co-morbid anxiety and/or depression in people with DM is not uncommon and it can not only lead to increased disease severity, complications, work disability, poor quality of life but is also associated with increased use of medical services and substantially higher health care costs. Hence it is extremely crucial for the developing world to estimate the prevalence of anxiety and depression and their associated factors amongst people with diabetes ${ }^{3-4}$.

In the present study, it was seen that generalized anxiety disorder was seen in $72(37.50 \%)$ of cases. These results were similar to the studies done in the past. The overall prevalence of GAD in cases of DM varies across the world and comprises 10 to $80 \%$ of the cases across the globe. According to a study done by Thour A et al, the anxiety of GAD score 5 or more was seen in $16(22 \%)$ of their 73 cases suffering from $\mathrm{DM}^{5}$. While in another study done in this context by Ganasegeran et al on cases of DM revealed that the anxiety was seen in 53(31.4\%) out of 169 cases. ${ }^{6}$ In comparison to this even higher results were seen by another study done by Khuwaja et al where $57.9 \%$ of cases suffering from DM had suffered from generalized anxiety disorder ${ }^{7}$. This explains that the chronic condition has been shown to have association with psychological issues like GAD. The prevalence varied due to difference in classes, socioeconomic status and availability of the resources of various countries.

The data from the present study has shown that the cases with poor socioeconomic status, and lower educational levels were also associated with higher number of cases to show GAD; though this difference was not statistically significant. Although, the cases who were un- employed had significantly higher number of cases suffering from this; affecting 58 out of 106 with $p=0.01$. This was also seen by the studies done in the past with variable results ${ }^{8-9}$. This can be explained by the factor that the cases with no job and also suffering from poor socio economic status are more vulnerable to suffer from this disease, because of the inability of them to afford the treatment and also the degree of various investigations for surveillance check-up for different complications associated with this. Reasons behind higher prevalence of anxiety and depressive disorders in developing countries as compared to the developed world are multifactorial. Some of the possibilities includes higher level of gender in equities, social in security, lack of education, poverty and financial difficulties. Economic stressors remains the key factor behind all these factors.

GAD was significantly high seen in females affecting 44 out of 94 cases with $p=0.03$. This was also seen by the study results of the past globally where females were more likely to suffer from this ${ }^{8-11}$. The study done by Bener et al has shown that more than $2 / 3^{\text {rd }}$ of the cases that were diagnosed with GAD were females ${ }^{8}$. According to another study by Palizgir et al this was seen significantly high in females with $p$ value of $<0.05$. The reason can be attributed to emotional liability, dependency and also the gender equality ${ }^{9}$. There was no significant difference in terms of various age group with $p$ value of 0.78 ; though majority of the cases were seen in age group 46 to 60 years. This was also seen in the past that the cases with higher age groups had more anxiety than younger ones; though no such cut off values were used as was used in the present study. This can be explained by the fact that higher age leads to more of dependency and emotional disturbance. Social isolation, more diseases and disabilities are the other common factors ${ }^{12-13}$.

The longer duration of the disease can also be another factor that can be a cause of GAD in higher age groups and so was seen in the same study and it was reported that the cases with duration of DM of 5 or more years had GAD significantly high (64 out of 120) cases with $p=0.01$. This was also seen in the past studies and can be due to various complications that are associated with longer duration of the disease as DM has linear correlation to the degree of various complication like renal, cardiac and ophthalmologic complications and so is seen with the GAD which is also very common. ${ }^{13}$ Regarding marital status, the cases, those were widow and divorced had highest number of cases with GAD i.e. 10 out of 14 and 9 out of 12 respectively with $p=0.001$. This was also supported by the studies that the cases that are single, unmarried and separated ones had more likelihood to develop such complication and can be multifactorial where dependency, social factors and cost of the treatment along with irreversible nature of the disease are salient ones ${ }^{14-15}$

\section{CONCLUSION}

GAD is common and seen in almost more than every $3^{\text {rd }}$ case suffering from DM and those with DM for 5 years or more, un-employed or those who were widow or divorced had it significantly high. 


\section{REFERENCES}

1. Wild S, Roglic G, Green A, Sicree R, King H. Global prevalence of diabetes: estimates for the year 2000 and projections for 2030. Diabetes Care. 2004;27(5):1047-53.

2. Wittchen HU, Zhao S, Kessler RC, Eaton WW. DSM-III-R generalized anxiety disorder in the National Comorbidity Survey. Arch Gen Psychiatry 1994; 51:355.

3. Kessler RC, Berglund P, Demler O. Lifetime prevalence and age-of-onset distributions of DSM-IV disorders in the National Comorbidity Survey Replication. Arch Gen Psychiatry 2005; 62:593.

4. Kessler RC, Gruber M, Hettema JM. Co-morbid major depression and generalized anxiety disorders in the National Comorbidity Survey follow-up. Psychol Med 2008; 38:365.

5. Wittchen HU, Jacobi F, Rehm J. The size and burden of mental disorders and other disorders of the brain in Europe 2010. Eur Neuro Psychopharmacol 2011; 21:655.

6. Wittchen HU, Jacobi F. Size and burden of mental disorders in Europe--a critical review and appraisal of 27 studies. Eur Neuro Psychopharmacol 2005; 15:357.

7. Wittchen HU, Kessler RC, Beesdo K. Generalized anxiety and depression in primary care: prevalence, recognition, and management. J Clin Psychiatry 2002; 63 Suppl 8:24.

8. Munk-Jørgensen P, Allgulander C, Dahl AA. Prevalence of generalized anxiety disorder in general practice in Denmark,
Finland, Norway and Sweden. Psychiatr Serv 2006; $57: 1738$

9. Lenze EJ. Anxiety disorders in the elderly. In: Textbook of Anxiety Disorders, 2nd ed. Stein DJ, Hollander E, Rothbaum BO (Eds), American Psychiatric Publishing, Inc. Washington, DC 2010; p.651.

10. Lin EH, Rutter CM, Katon W. Depression and advanced complications of diabetes: a prospective cohort study. Diabetes Care. 2010;33(2):264-269.

11. Lin EH, Katon W, Von Korff M. Relationship of depression and diabetes self-care, medication adherence, and preventive care. Diabetes Care. 2004;27(9):2154-60.

12. Gilmer TP, O'Connor PJ, Rush WA. Predictors of health care costs in adults with diabetes. Diabetes Care. 2005;28(1):59-64.

13. de Groot M, Doyle T, Hockman E, Wheeler C, Pinkerman B, Shubrook J. Depression among type 2 diabetes rural Appalachian clinic attendees. Diabetes Care. 2007; 30:1602-4

14. Guariguata L, Whiting DR, Hambleton I, Beagley J, Linnenkamp U, Shaw JE. Global estimates of diabetes prevalence for 2013 and projections for 2035. Diabetes Res Clin Pract. 2014;103:137-49.

15. Vaz NC, Ferreira AM, Kulkarni MS. Prevalence of diabetic complications in rural Goa, India. Indian J Community Med. 2011;36:283-86. 